\title{
Effects of Sports On Social Anxiety and Subjective Well-Being Levels of University Students
}

\author{
Aygül Çağlayan Tunç ${ }^{1}$, Mehibe Akandere ${ }^{2}$ \\ ${ }^{1}$ Sport Science Faculty, Sport Psychology, Turkey \\ ${ }^{2}$ Selçuk University Sport Science Faculty, Turkey \\ Correspondence: Aygül Çağlayan Tunç, Sport Science Faculty, Sport Psychology, Turkey.
}

Received: October 8, 2019

Accepted: October 23, $2019 \quad$ Online Published: November 3, 2019

doi:10.11114/jets.v8i1.4552

URL: https://doi.org/10.11114/jets.v8i1.4552

\begin{abstract}
The aim of this study is to examine the effects of social anxiety and subjective well-being levels of university students. Totally 600 students from the University of Konya, Konya, Turkey. Social Anxiety and subjective well-being tests are applied on participants. The statistical package program Spss 16.0 is used in order to analyze the data. The t test and variance analyzer (ANOVA) is used for independent groups while Tukey's test was used as multiple comparison tests for differences. The relationship between consistent data is being tested via pearson. Well-being scores of male or female students who do not do sports $(\mathrm{P}<0.05)$. Being criticized scores of men are not doing sports $(\mathrm{P}<0.05)$. Social avoidance scores were higher than boys $(\mathrm{P}<0.05)$. Consequently, it is seen as a self-being level.
\end{abstract}

Keywords: university students, sport, social anxiety, subjective well-being

\section{Introduction}

In addition to being a set of physical activities, sport is a phenomenon that helps individuals to socialize by giving people a sense of individual and social identity and a sense of group membership (Küçük \& Koç, 2004). Social anxiety is one's exaggerated fear of being a focus of attention and being negatively evaluated and considered worthless by another person or persons. Social anxiety is a type of anxiety that is expected to be experienced especially in social relations. People with social anxiety problems; Increased levels of physiological arousal, attention difficulties in collecting, anxiety symptoms such as tension noun they show. However, people with social concerns are aware that the source of their discomfort is the social interaction they are experiencing or experiencing. There have been times when everyone felt tense before a job interview or a meeting, but it is accepted that people who show this consistently, that is, functionality is negatively affected, are social anxiety (Burger , 2006). Social anxiety is not only related to how a person is perceived and evaluated by others, but also the possibility of being evaluated (Çakır , 2010). In this context, it can be said that social anxiety is a phenomenon that negatively affects social functionality and social relations. University students experience anxiety in many areas. Course selection, exam anxiety, academic competition, evaluation system, relations with faculty members and classmates, difficulty in course content, academic jobs and difficulties in meeting personal needs are important sources of stress for university students (Gizir , 2005). In this respect, university students are more likely to experience social anxiety. Social anxiety of young people can also affect their friendship relationships. Most of the social relations among young people consist of peer relations (Zorbaz, 2013). These relations are vital in ensuring the harmony of the individual with the environment.

It can be said that subjective well-being consists of a combination of three elements that are related to each other: (a) positive affect, (b) negative affect, and (c) life satisfaction . According to this definition, the concept of subjective well-being, in general, appears to include a general assessment of the individual's feelings and thoughts about his / her life (Türkdoğan $\&$ Duru, 2012). Although these distinctive features limit the subject area, subjective well-being has been described in various ways in the relevant literature. Subjective well-being is defined as evaluating one's life as cognitive and emotional. This assessment includes emotional responses to events and cognitive assessment of satisfaction. People experience high subjective well-being when engaging in engaging activities, experiencing a lot of joy and little pain and being satisfied with their lives. There are other characteristics related to good life and mental health, but subjective well-being focuses on one's own assessment of his or her life ( Dost, 2007). The subjective well-being of university students is important in society. The future prosperity of a country depends on the subjective well-being of students in that country. Determining the factors 
affecting subjective well-being and taking measures to reduce the variables that negatively affect subjective well-being will enable them to become happier individuals in the future (Y1lmaz, 2014).

Personal devolopment of universtiy students goes on and it has to find its own identity, adopt the national and universal values of society, adapt and reach maturity. Therefore, coping efforts and psychological well-being appear. Therefore, it is important that they adapt to social life and develop healthy social relations. In this respect, the needs of university students, problems, adaptation processes to the university environment, professional attitudes, opportunities to benefit from psychological services, university psychological services should be examined in a more comprehensive manner and the results should be better structured in terms of student personality services (Taşgit, 2012). It is possible for individuals to gain a social environment and realize themselves through sports activities (Tilki , 2011). In addition to having an important function in the healthy development of an individual, sport activities also contribute positively to social and emotional development. These activities make functionalities such as creativity and leadership functional, and develop personality characteristics such as being challenging, determined, harmonious, productive, determined, respectful and understanding, obeying rules, cooperating, acting independently, self-discipline, hardworking and diligent. Terzi, 2011). In this context, the most effective medicine that will help the university student to get rid of the problems and contribute to his socialization is to do sports . In this respect, the study of social anxiety and subjective well-being of university students who do sports and not do sports is the focus of this research.

\section{Material and Method}

\subsection{Research Model}

This study is a randomized sample method used to test whether sports affect university students' social anxiety and subjective well-being and whether this effect differs according to gender variable. $\mathrm{B} u$ in the context of survey research also was conducted with the relational model of the scanning pattern. Correlational model object in two or more variables that there is a change between with and to determine its degree (Karasar, 2012).

\subsection{Population and Sample of the Research}

The population of the study consists of students studying at various faculties of Selçuk University, and the sample of the study consists of 600 students who study in the departments of Sports Sciences, Medicine, Dentistry, Agriculture, English Language Literature and Conservatory. In this study, a total of 158 people were included in the study and 442 people were considered as not doing sports. Volunteering principle was used in the application of the scales to the sample group.

\subsection{Data Collection Tools}

In the study, 'Personal Information Form' prepared by the researcher to determine some personal characteristics of the participants and 'Social Anxiety Scale' to determine social anxiety levels; Subjective Well-being Scale (SIS) was used to determine subjective well-being levels. The Personal Information Form contains questions about the gender of university students and whether they do sports.

\subsubsection{Social Anxiety Scale}

The Social Anxiety Scale was developed by Özbay and Palanc1 (2001) in order to determine the problems of social anxiety experienced by university students. The scale, which was developed to have usefulness for the university student population, was prepared to measure the skills and concerns of university students in accordance with social situations. The test was subjected to criteria and construct validity. For criterion validity, five related scales of the SCL-90 scale, Rathus assertiveness inventory and Social introversion subtest of MMPI test were used. As a result of factor analysis for construct validity, a three-factor test structure consisting of 30 items was formed. In the factor analysis, factorisability was examined with different methods. Sample suitability and Sphericity tests were performed. KMO was found to be 0.90, Barlett Sphericity 3644.58 and $p<0.001$. In the first factor analysis, the maximum number of significant factors was examined by scree-test. It was determined that the number of factors that were appropriate and explained was three. These three factors, which were obtained with the results of Varimax rotation factor analysis, were named as (1) social avoidance, (2) critical anxiety and (3) sense of individual worthlessness. The total variance explained by three factors was 32.9\% (Özbay and Palancı, 2001).

\subsubsection{Subjective Well-Being Scale}

Subjective well-being scale was developed by Dost (2004) consists of 46 items. The scale measures subjective well-being by determining the frequency and intensity of positive and negative emotions. The contents of the items were examined and the factors ; life, their own past and the life of others, positive and negative emotions, goals, self-confidence, optimism, interest activities, friendship relations, looking at the future, family relationships, coping with the difficulties of life in the life of others and pessimism names are given. Reliability of Subjective Well-being Scale: Reliability of the scale was determined in two ways. Firstly, the Cronbach's alpha reliability coefficient of the scale was calculated as 93 by 
using the data of 46 items taken as a result of factor analysis in the same application. Subjective Well-Being Scale Scoring: Answering system for each statement "totally appropriate (5)", "mostly appropriate (4)", "Partially Eligible (3)", "A little Available (2)" and "Never Not Applicable (1) It is in the form of five 1 ikert scale. The scores of each item ranged from "5 to $1 " .26$ of the items were negative. Negative expressions are items $2,4,6,10,13,15,17,19,21,24,26,28,30,32,35$, $37,38,40,43$ and 45 . Scoring of negative expressions is done by reversing. The lowest score that can be obtained from the scale is 46, the highest score is 230, and the high score indicates that subjective well-being is high (Dost , 2005). In this study, Cronbach's alpha reliability coefficient heat obtained from Subjective Well-Being Scale was calculated to be 0,702 .

\section{Findings}

As a result of the study conducted to examine the effect of sports on the social anxiety and subjective well- being levels of university students, the following findings were obtained.

Table 1. Comparison of social avoidance, critique, worthlessness, total social anxiety and subjective well-being scores of the participants according to whether or not to do sports

\begin{tabular}{|c|c|c|c|c|c|c|}
\hline Variables & & $\mathrm{N}$ & Average & Std. Deviation & $\mathrm{t}$ & $\mathrm{p}$ \\
\hline \multirow{2}{*}{ Social avoidance } & Sports & 158 & 13,12 & 9.577 & \multirow{2}{*}{-1.457} & \multirow{2}{*}{.146} \\
\hline & Non-sports & 442 & 14.25 & 7.881 & & \\
\hline \multirow{2}{*}{ Criticization } & Sports & 158 & 13,48 & 7,630 & \multirow{2}{*}{-2.610} & \multirow{2}{*}{$\begin{array}{l}0,009 \\
*\end{array}$} \\
\hline & Non-sports & 442 & 15.23 & 7.075 & & \\
\hline \multirow{2}{*}{ insignificance } & Sports & 158 & 8.68 & 6,310 & \multirow{2}{*}{-1.533} & \multirow{2}{*}{.126} \\
\hline & Non-sports & 442 & 9.57 & 6.294 & & \\
\hline \multirow{2}{*}{ Social anxiety total score } & Sports & 158 & 35.33 & 21.517 & \multirow{2}{*}{-1.925} & \multirow{2}{*}{0,055} \\
\hline & Non-sports & 442 & 38.91 & 19.499 & & \\
\hline \multirow{2}{*}{ Subjective well-being } & Sports & 158 & 157.99 & 22.601 & \multirow{2}{*}{3,350} & \multirow{2}{*}{$\begin{array}{l}0.001 \\
*\end{array}$} \\
\hline & Non-sports & 442 & 151.72 & 19.264 & & \\
\hline
\end{tabular}

$* \mathrm{P}<0.05$

When Table 1 was examined, the social avoidance, critique, worthlessness, total social anxiety and subjective well-being scores of the participants were compared according to whether they do sports or not, and the scores of those who did not do sports were significantly higher than those who did sports $(\mathrm{P}<0), 05)$. On the other hand, subjective well-being scores of non-sports participants were found to be significantly lower than the subjective well-being scores of those who did sports $(\mathrm{P}<0.05)$. In addition, it was found that the total scores of social avoidance, worthlessness and social anxiety did not differ between those who do sports and those who do not ( $\mathrm{P}>0.05)$.

Table 2. Comparison of social avoidance, criticization, worthlessness, total social anxiety and subjective well-being scores of the participants according to gender

\begin{tabular}{|c|c|c|c|c|c|c|}
\hline Variables & Gender & $\mathrm{N}$ & Average & Std. Deviation & $\mathrm{t}$ & $\mathrm{p}$ \\
\hline \multirow{2}{*}{ Social avoidance } & Woman & 301 & 14,62 & 8.480 & \multirow{2}{*}{1,981} & \multirow{2}{*}{$0,048 *$} \\
\hline & Male & 299 & 13,27 & 8.211 & & \\
\hline \multirow{2}{*}{ Criticization } & Woman & 301 & 15,10 & 7.777 & \multirow{2}{*}{1,133} & \multirow{2}{*}{.258} \\
\hline & Male & 299 & 14.43 & 6.694 & & \\
\hline \multirow{2}{*}{ insignificance } & Woman & 301 & 9.83 & 6.689 & \multirow{2}{*}{1,917} & \multirow{2}{*}{0,056} \\
\hline & Male & 299 & 8.84 & 5,863 & & \\
\hline \multirow{2}{*}{ Social anxiety total score } & Woman & 301 & 39.56 & 21.113 & \multirow{2}{*}{1,953} & \multirow{2}{*}{0,051} \\
\hline & Male & 299 & 36.36 & 18.913 & & \\
\hline \multirow{2}{*}{ Subjective well-being } & Woman & 301 & 152.04 & 21.183 & \multirow{2}{*}{-1.609} & \multirow{2}{*}{.108} \\
\hline & Male & 299 & 154.72 & 19.451 & & \\
\hline
\end{tabular}

$\mathrm{P}<\overline{0.05}$ 
When Table 2 was examined, the social avoidance scores of the participants were significantly higher than the social avoidance scores of men $(\mathrm{P}<0,05)$. On the other hand, it was found that there was no significant difference in terms of gender, in terms of critique, worthlessness, total social anxiety and subjective well-being $(\mathrm{P}>0.05)$.

Table 3. Comparison of the social avoidance, critique, worthlessness, total social anxiety and subjective well-being scores of the female participants according to whether they do sports or not

\begin{tabular}{|c|c|c|c|c|c|c|}
\hline \multicolumn{2}{|c|}{ The status of women participating in the study } & $\mathrm{N}$ & Average & Std. Deviation & $\mathrm{t}$ & $\mathrm{p}$ \\
\hline \multirow{2}{*}{ Social avoidance } & Sports & 93 & 14,16 & 9.049 & \multirow{2}{*}{-0.633} & \multirow{2}{*}{.527} \\
\hline & Non-sports & 208 & 14,83 & 8.227 & & \\
\hline \multirow{2}{*}{ Criticization } & Sports & 93 & 13,84 & 7.744 & \multirow{2}{*}{-1.894} & \multirow{2}{*}{.059} \\
\hline & Non-sports & 208 & 15,67 & 7.744 & & \\
\hline \multirow{2}{*}{ insignificance } & Sports & 93 & 8.85 & 6.571 & \multirow{2}{*}{-1.701} & \multirow{2}{*}{0,090} \\
\hline & Non-sports & 208 & 10.26 & 6,711 & & \\
\hline \multirow{2}{*}{ Generic anxiety total } & Sports & 93 & 36.94 & 21.222 & \multirow{2}{*}{-1.444} & \multirow{2}{*}{0,150} \\
\hline & Non-sports & 208 & 40.73 & 21.009 & & \\
\hline \multirow{2}{*}{ Subjective well-being } & Sports & 93 & 156.58 & 23.255 & \multirow{2}{*}{2,507} & \multirow{2}{*}{$0,013 *$} \\
\hline & Non-sports & 208 & 150.01 & 19.914 & & \\
\hline
\end{tabular}

$* \mathrm{P}<0.05$

When Table 3 was examined, when the social avoidance, criticization, worthlessness, total social anxiety and subjective well-being scores of the participants were compared according to their status of doing sports, the subjective well-being scores of the women doing sports were significantly higher than the subjective well-being scores of non-sports women. It was found to be high $(\mathrm{P}<0.05)$. On the other hand, it was found that the social avoidance, criticization, worthlessness and total social anxiety scores of the female participants did not show a significant difference according to the status of doing sports $(\mathrm{P}>0.05)$.

Table 4. Comparison of social avoidance, critique, worthlessness, total social anxiety and subjective well-being scores of male participants according to whether or not to do sports

\begin{tabular}{|c|c|c|c|c|c|c|}
\hline \multicolumn{2}{|c|}{ The status of the men participating in the study } & $\mathrm{N}$ & Average & Std. Deviation & $\mathrm{t}$ & $\mathrm{p}$ \\
\hline \multirow{2}{*}{ Social avoidance } & Sports & 65 & 11,63 & 10,171 & \multirow{2}{*}{-1.831} & \multirow{2}{*}{0,068} \\
\hline & Non-sports & 234 & 13.73 & 7.540 & & \\
\hline \multirow{2}{*}{ Criticization } & Sports & 65 & 12.97 & 7.494 & \multirow{2}{*}{-2.001} & \multirow{2}{*}{$0,046 *$} \\
\hline & Non-sports & 234 & 14.84 & 6,413 & & \\
\hline \multirow{2}{*}{ insignificance } & Sports & 65 & 8.43 & 5.958 & \multirow{2}{*}{-0.640} & \multirow{2}{*}{.523} \\
\hline & Non-sports & 234 & 8.96 & 5.844 & & \\
\hline \multirow{2}{*}{ Generic anxiety total } & Sports & 65 & 33.03 & 21.891 & \multirow{2}{*}{-1.609} & \multirow{2}{*}{0,109} \\
\hline & Non-sports & 234 & 37.29 & 17.941 & & \\
\hline \multirow{2}{*}{ Subjective well-being } & Sports & 65 & 160.02 & 21.649 & \multirow{2}{*}{2,505} & \multirow{2}{*}{$0,013 *$} \\
\hline & Non-sports & 234 & 153.24 & 18.578 & & \\
\hline
\end{tabular}

$* \overline{\mathrm{P}<0.05}$

When Table 4 was examined, when the social avoidance, criticization, worthlessness, total social anxiety and subjective well-being scores of the male participants were compared in terms of doing and not doing sports, the subjective well-being scores of the men doing sports were significantly higher than the subjective well-being scores of the non-sports men. ( $\mathrm{P}<0.05)$. On the other hand, the male participants who participated in the study were significantly lower than the male participants who did not engage in sports $(\mathrm{P}<0.05)$. In addition, it was found that the social avoidance, worthlessness and total social anxiety scores of male participants did not show a significant difference according to whether or not to do sports $(\mathrm{P}>0.05)$. 


\section{Discussion and Conclusion}

As a result of this study conducted to investigate the effect of sport on social anxiety and subjective well-being of university students ; a those who make sport of the participants to be criticizing the raştır scores points not criticizing those who sport was significantly higher $(\mathrm{P}<0.05)$. The subjective well-being scores of the non-sportsmen were found to be lower than those of the sportsmen $(\mathrm{P}<0.05)$. In addition, it was found that the total scores of social avoidance, worthlessness and social anxiety differed among those who do sports and those who do not ( $\mathrm{P}>0.05)$. Comparing in terms of the gender of the participants in the study, women's social avoidance scores were significantly higher than in male social avoidance scores $(\mathrm{P}<0.05)$. On the other hand, it was found that there were no significant differences between the genders in terms of critique, worthlessness, total social anxiety and subjective well-being . $(\mathrm{P}>0.05)$. The research that Gümüş (2002) made, reached the conclusion that change according to gender social concerns. From a gender perspective of cultural factors in another study, subjective well-being has stated that it can differentiate their level and made it the parallel female students to the results of research in subjective well-being mean scores of male students in was higher than the average score and friends was no significant difference (2004) has indicated. In a study conducted by İzgiç et al . (2000) on university students, the prevalence of social anxiety in women was reported to be $8.9 \%$ and $7.1 \%$ in men. In addition to the studies that show that social anxiety is more common in women than men, there are also studies showing that it is more common in men. In this study s failure to find any difference between the sexes in terms of ow did Social anxiety; It is thought that the students included in the research are students from the same university and in this context, similar social activities, having similar social spaces, living in the same cultural environment.

In the study, subjective well-being scores of women who do sports were significantly higher than women who did not do sports $(\mathrm{P}<0.05)$. On the other hand, it was found that the social avoidance, critique, worthlessness and total social anxiety scores of the female participants showed a significant difference according to whether or not to do sports $(\mathrm{P}>0.05)$. In the study, subjective well-being scores of the men doing sports were found to be significantly higher than the men who did not do sports $(\mathrm{P}<0.05)$. On the other hand, the scores of men who did sports were significantly lower than those of men who did not do sports $(\mathrm{P}<0.05)$. In addition, it was found that the social avoidance, worthlessness and total social anxiety scores of male participants did not show a significant difference according to whether or not to do sports $(\mathrm{P}>0.05)$. To the ydın (2011), university students, his research on water in , burying gender in general self-efficacy level of students re reached the conclusion that is different is Her. Accordingly, the gender characteristics of the participants affect the general self-efficacy levels. Men's overall self-efficacy is higher than that of women. The reason for this is that the male individuals in our society can move more easily without fear of being misunderstood and that they are more aggressive than women in entering social environments. This finding in the literature shows that males are slightly more advantageous in terms of self-efficacy than females.

As a result; sports and social concerns of college students' subjective well-being levels to get the effect that the purpose of the examination has been shown to work in the sports of college students have a positive effect on the level of subjective well-being and social concerns. The data of the study shows that social anxiety and subjective well-being levels positively affect sports . For this reason, it is seen that the social anxiety and subjective well-being levels of university students have a positive effect on sports.

In this context ;

- Sports activities should be encouraged in universities and efforts should be made to benefit these large masses ,

- University students are increasing and promoting the sport of sports fields required importance to sports facilities should give.

- Sports instructors that work in the universities must be increased.

- In some universities, the importance of the sports course taught as an elective course for the youth of the university should be known and sports courses should be included as an elective course in all departments of the universities. Especially, the students who are enrolled in the first year of the university should be introduced to the sports facilities of the university and how the students can benefit from them .

- Families should be made aware of the sport and its benefits .

- Sports activities should be handled by the media and young people should be encouraged to play sports through the media.

- If the above items are given due attention, the fact that university students, and therefore the youth of the country, are psychologically healthy individuals is vital to life satisfaction and to raise happy people. 


\section{References}

Aydiner, B. (2011). Examination of sub-dimensions of university students' life goals according to general self-efficacy life satisfaction and various variables. ( Unpublished master's thesis ). Sakarya University, Institute of Educational Sciences, Sakarya.

Burger J. M. (2006). Personality (Translated: İnan Deniz Erguvan Sarıŏlu), ( 1st Edition ). Kaknüs Publications, Istanbul.

Cakir, S. (2010). The effect of the social anxiety coping program based on the cognitive-behavioral approach on the social anxiety levels of high school students (Master's thesis, Uludağ University, Institute of Social Sciences, Bursa).

Dost, M. T. (2004). Subjective well-being of university students (Unpublished doctoral dissertation, Hacettepe University, Institute of Social Sciences, Ankara).

Dost, M. T. (2005). Development of Subjective Well-being Scale: Validity and reliability study. Turkish Journal of Psychological Counseling and Guidance, 3(23), 103-111.

Dost, M. T. (2007). Examination of life satisfaction of university students according to some variables. Pamukkale University Faculty of Education Journal, 2(22), 132-143.

Gizir, C. A. (2005). A study on the problems of Middle East Technical University senior students. Mersin University Journal of the Faculty of Education, 1(2), 196-213.

Gümüş, E. (2002). The effect of the social anxiety coping program on the social anxiety levels of university students. ( Unpublished doctoral dissertation). Ankara University Institute of Educational Sciences, Ankara.

Izgic, F., Akyüz G., Dogan, O., \& Swan, N. (2000). Prevalence of social phobia among university students . Anatolian Journal of Psychiatry, 1(4), 207-214.

Karasar, N. (2012). Scientific research method (23rd edition). Ankara, Nobel Publishing House.

Küçük, V., \& Koc, H. (2004). The relationship between human and sport in the process of psycho-social development. Dumlupinar University Journal of Social Sciences, 10, 131-141.

Özbay, Y., \& Palanc1, M. (2001). Social Anxiety Scale: Validity and Reliability Study, VI National Psychological Counseling and Guidance Congress, Ankara, METU, 5-7 September.

Taşgit, M. S. (2012). Examination of self-esteem and decision-making levels of university students. (Master's thesis, Karamanoğlu Mehmetbey University Institute of Social Sciences, Karaman).

Terzi, G. (2011). Comparison of self-acceptance levels of visually impaired students between 13 and 18 years of age and active sports. (Master 's thesis, Gazi University Institute of Educational Sciences, Ankara).

Tilki, F. (2011). Physical education and sports education students' perception of the level of community service practices: The case of Sakarya province. (Graduate $t$ crush, Sakarya University Training Institute im Sciences, Sakarya).

Turkdogan, T., \& Duru, E. (2012). The role of meeting basic needs in predicting subjective well-being among university students. Educational Sciences in Theory and Practice, 12(4), 2429-2446.

Yilmaz, S. D. (2014). Subjective well-being of prospective teachers: a research in the department of physical education and sports teaching in anatolian university. International Journal of Social Research, 7(35), 651-657.

Zorbaz, O. (2013). Investigation of problematic internet use of high school students in terms of social anxiety and peer relationships. (Master's thesis, Hacettepe University Institute of Social Sciences, Ankara).

\section{Copyrights}

Copyright for this article is retained by the author(s), with first publication rights granted to the journal.

This is an open-access article distributed under the terms and conditions of the Creative Commons Attribution license which permits unrestricted use, distribution, and reproduction in any medium, provided the original work is properly cited. 